\title{
La recepción de los golpes de Estado de Chile y Argentina en Venezuela: prensa, actores políticos y gobiernos (1973/1976)
}

\author{
The reception of the coups d'état of Chile and Argentina in Venezuela: press, \\ political actors and governments (1973/1976)
}

Mario Ayala* \& Claudia Rojas Mira**

\begin{abstract}
Resumen: El artículo reconstruye y analiza las posiciones de la prensa nacional, los partidos políticos, los sindicatos y los gobiernos venezolanos ante los golpes de Estado de Chile (septiembre de 1973) y la Argentina (marzo de 1976) en las semanas previas y posteriores a los sucesos, apoyado en el estudio de la prensa periódica de tirada nacional y de bibliografía histórica específica. El análisis de estas coyunturas en la esfera pública y política venezolana de la década de 1970 constituye un problema de investigación relevante para conocer las percepciones y representaciones sociales de distintos actores estatales y no estatales de la época, así como sus respuestas en la forma de posicionamientos públicos y activación de solidaridades y políticas particulares en relación a cada caso.
\end{abstract}

Palabras clave: Venezuela, Golpe de Estado, Chile, Argentina, Partidos Políticos, Sindicatos, Gobiernos.

\begin{abstract}
The article reconstructs and analyzes the positions of the national press, political parties, unions and Venezuelan governments in the face of the coup d'état of Chile (September 1973) and Argentina (March 1976) in the weeks before and after the coups. The analysis of these conjunctures in the Venezuelan public and political sphere of the 1970s constitutes a relevant research problem to know the perceptions and social representations of different state and non-state actors of the time, as well as their responses in the form of public positions and activation of specific solidarities and policies in relation to each case.
\end{abstract}

Key words: Venezuela, Coup d'état, Chile, Argentina, Political Parties, Trade Unions, Governments.

\footnotetext{
*Argentino. Coautor. Profesor de Historia y doctorando del Doctorado en Historia de la Universidad de Buenos Aires (UBA). Becario doctoral UBA en el Instituto Interdisciplinario de Estudios e Investigaciones sobre América Latina de la Facultad de Filosofía y Letras-UBA. Correo electrónico: marioayala@ filo.uba.ar ${ }^{* *}$ Chilena. Coautora. Doctora en Historia. Investigadora del Centro de Estudios Avanzados (CEA) / Universidad de Playa Ancha, Valparaíso. Proyecto CONICYT + FONDECYT/Postdoctorado 2016 + 3160229, titulado "El exilio político chileno en Venezuela: Coincidencias históricas y lecciones políticas (1973-1989)". Correo electrónico: claudia.fedora@upla.cl Agradecemos los comentarios críticos realizados a este texto por los dos evaluadores anónimos seleccionados por la Revista Izquierdas, los cuales han contribuido a mejorar de forma sustancial este artículo
} 
Recibido: 27 noviembre 2016

Aceptado: 19 marzo 2017

\section{Introducción}

Durante las décadas de 1960 y 1970 se instalaron en el Cono Sur de América Latina Dictaduras de Seguridad Nacional (DSN) cuyas políticas represivas, violatorias de derechos humanos, civiles y políticos provocaron desapariciones forzadas, encarcelamientos, asesinatos y destierros masivos de activistas políticos, sociales, gremiales e intelectuales cuyo espectro político-ideológico fue mucho más allá de las diversas izquierdas de la época. Entre estas dictaduras, las de Chile y Argentina se caracterizaron por la aplicación de las formas más violentas y masivas de represión de opositores mediante la utilización sistemática de torturas, campos de concentración, desapariciones forzadas, prisión política, persecuciones y exilios políticos. A su vez, ambas dictaduras, buscaron violentar y eliminar a opositores y actores críticos de su política en terceros países, tanto mediante mecanismos de coordinación entre Estados dictatoriales como a través de operaciones encubiertas que violaban la soberanía de otros países ${ }^{1}$.

En el contexto de la Guerra Fría en América Latina en su etapa posterior a la Revolución Cubana, los golpes de Estado en Chile (1973) y la Argentina (1976), gozaron de una receptividad diferenciada dependiendo del impacto que tuvieron en las esferas públicas y políticas de los distintos países y regiones, dando cuenta de las atmósferas locales en las cuales se evidenciaron los conflictos y tensiones desarrollados durante el periodo $^{2}$. En este sentido, no debe perderse de vista que los golpes de Estado y las dictaduras chilena y argentina se dieron en una época de globalización transnacional y esferas públicas internacionales importantes y gravitantes sobre la política interna de los Estados $^{3}$. Es por ello que, las experiencias de los golpes de Estado en Chile y en la Argentina, no siendo las únicas, se hicieron más visibles y significativa que otras, en los distintos países del orbe. Este hecho implicó, por una parte, que el mundo se abriera para recibir a los perseguidos políticos producto del contexto político nacional y, por otra, que

\footnotetext{
${ }^{1}$ Véase al respecto Melisa Slatman, "Terrorismo de Estado y exilio: hipótesis exploratorias para una comparación entre los casos chileno y argentino", Ponencia presentada en Jornadas de trabajo sobre Exilios Políticos del Cono Sur en el siglo XX. Agendas, problemas y perspectivas conceptuales, Facultad de Humanidades y Ciencias de la Educación de la Universidad Nacional de La Plata, 26, 27 y 28 de septiembre de 2012; Patrice Mc Sherry, J. "La maquinaria de muerte: la Operación Cóndor", Taller (Segunda Época). Revista de Sociedad, Cultura y Política en América Latina, Vol. 1, ํำ (octubre), pp. 33-45.

${ }^{2}$ Acerca de los avatares de la Guerra Fría en el contexto global y en el local está el trabajo de, Odd Arne Westad, The Global Cold War. Third World Interventions and the Making of our Times, Cambridge, Cambridge University Press, 2007. Específicamente para América Latina son fundamentales los trabajos de Daniela Spenser (ed.), Espejos de la Guerra fría: México, América Central y el Caribe, México, CIESAS, 2004; y Tanya Harmer, Allende's Chile and the inter-American cold war, North Carolina, The University of North Carolina Press, 2011.

${ }^{3}$ Véase al respecto Arturo Aguirre, Antolín Sánchez Cuervo y Luis Roniger, Tres estudios sobre el exilio: condición humana, experiencia histórica y significación política, Madrid-México, EDAF-BUAP, 2014, p. 13.
} 
la situación de los Derechos Humanos en el Cono Sur y de los exiliados cobrara una importancia internacional nunca antes vista.

La recepción de los golpes militares del ciclo de dictaduras de Seguridad Nacional en el Cono Sur (1964-1991) en la esfera pública venezolana aún no ha sido abordada de forma sistemática por la investigación académica. En este artículo analizamos la recepción del golpe chileno y argentino en Venezuela mediante un contrapunto comparativo que favorezca la reconstrucción y comprensión de los posicionamientos discursivos y las prácticas de actores claves de la esfera pública política local como fueron la prensa, los partidos políticos, los sindicatos y el gobierno en las semanas previas y posteriores a los sucesos. El análisis de estas coyunturas en la esfera pública y política venezolana de la década de 1970 constituye un problema de investigación relevante para conocer las percepciones y representaciones sociales de distintos actores estatales y no estatales de la época, así como sus respuestas en la forma de posicionamientos y activación de solidaridades en relación a cada caso.

En el trazado metodológico estos interrogantes de investigación imponen la necesidad de indagar en la dimensión comparativa del fenómeno, formulando preguntas y paradigmas interpretativos comunes que ayuden a una mejor definición de las mismas especificidades que caracterizan los diferentes contextos locales. Por ello, se hace necesario hacer un ejercicio de Historia Comparada para analizar un fenómeno como este, que dado el desarrollo de nuestra disciplina ya no es posible explicarlo sin la concurrencia de la comparación (e interrelación creciente) entre países y regiones. Nuestra convivencia con la cultura política de los países seleccionados y el dominio de sus contextos sociohistóricos nos permite arriesgarnos en esta propuesta comparada. En este sentido, siguiendo a Charles Maier consideramos que:

Incluso frente a todas estas dificultades metodológicas, sería un error, sin embargo, renunciar a una historiografía comparada. Cualquier discurso histórico debe contener elementos basados en el método comparativo y debe apoyarse en generalizaciones, al menos en la de la existencia de una experiencia humana común. También los puntos de vista de tipo más hermenéutico presuponen una comprensión humana general ante las angustias de la elección histórica: la insistencia sobre una subjetividad común se convierte en la condición objetiva irrenunciable a la hora de escribir historia ${ }^{4}$.

El enfoque comparativo nos permite conocer los imaginarios y representaciones de la sociedad venezolana de la época en relación a las sociedades chilena y argentina, e interrogarnos cómo estos pudieron incidir en los diferentes tratamientos que recibieron los golpes de Estado de ambos países en las esferas públicas y políticas, de donde surgirán los contrastes entre uno y otro caso y la búsqueda de explicaciones sobre esas diferencias y coincidencias $^{5}$.

\footnotetext{
${ }^{4}$ Charles S. Maier, "La historia comparada”, Studia Historica-Historia Contemporánea, Vol. X-XI (199293), p. 32.

${ }^{5}$ Para una importante reflexión sobre la metodología comparada en el análisis histórico y su aplicación véase:
} 
Las fuentes en que se apoya la investigación fueron la prensa venezolana de la época, de tirada nacional (los diarios El Nacional y El Universal) y prensa específica de partidos o sindicatos, así como bibliografía histórica específica. El artículo se organiza en tres apartados. En el primero de ellos se analiza la recepción del golpe de Estado chileno en los principales diarios, los partidos políticos, los sindicatos y el gobierno nacional. En el segundo apartado se realiza el mismo ejercicio para el caso del golpe de Estado argentino. El tercer apartado presenta las conclusiones finales.

\section{La posición de Venezuela frente a los sucesos en el Chile de 1973}

El golpe de Estado del 11 de septiembre de 1973 contra el gobierno del presidente Salvador Allende, instauró una dictadura feroz que persiguió, asesinó, encarceló y sembró el terror entre la militancia de la Unidad Popular (UP), los simpatizantes del gobierno y la población en general. En aquel momento gobernaba Venezuela el socialcristiano Rafael Caldera (1969-1974) cercano al Partido Demócrata Cristiano (PDC) chileno, cuyo sector hegemónico incentivó, justificó y apoyó el golpe de Estado con el argumento de que los militares debieron actuar forzados "por las circunstancias de un país al borde de la guerra civil"" que llevarían a la instauración de una la dictadura marxista. Así las cosas, la posición del gobierno de Caldera ante los hechos acaecidos en La Moneda y la muerte del presidente Salvador Allende fue moderada y de reconocimiento de la situación política de facto. Las relaciones entre ambos gobiernos habían sido frías y distantes debido al distinto enfoque político ideológico de sus gobernantes ${ }^{7}$. Pero la relación bilateral fue de respeto mutuo de acuerdo a los principios de política exterior de Caldera, el "pluralismo ideológico", la "justicia internacional" y la "integración latinoamericana", que abandonaban la "Doctrina Betancourt" que durante los gobiernos de Acción Democrática AD- (Rómulo Betancourt y Raúl Leoni 1959-1969) había fundado la política exterior venezolana en los principios de defensa de la democracia y el no reconocimiento y ruptura automática de relaciones diplomáticas con gobiernos de facto que llegaran al poder mediante un golpe de Estado ${ }^{8}$.

Aunque las relaciones previas entre el gobierno de Allende y el de Rafael Caldera no tuvieron el entusiasmo que hubo con otras presidencias de la región, como la de Luis

María Soledad, Lastra, Los retornos del exilio en Argentina y Uruguay. Una historia comparada de las políticas y tensiones en la recepción y asistencia en las pos dictaduras (1983-1989), Tesis para optar por el grado de Doctora en Historia, La Plata, Argentina, Universidad Nacional de La Plata, 2014.

${ }^{6}$ Documento del Departamento Internacional del PDC dirigido a los "Partidos demócrata-cristianos y a personalidades mundiales", citado en Raffaele Nocera, "11 de septiembre de 1973: incomprensiones y ambigüedades entre la DC chilena y la italiana”, en Izquierdas, No 24, 2015, p. 5.

${ }^{7}$ Joaquín Fermandois, Chile y el mundo 1970-1973. La política exterior del gobierno de la Unidad Popular y el sistema internacional. Santiago, Universidad Católica de Chile, 1985.

${ }^{8}$ Véase al respecto Raquel Gamus, "El contenido de la política exterior de Carlos Andrés Pérez (19741979)", Anuario del instituto de Estudios Hispanoamericanos, Ediciones de la Facultad de Humanidades y Educación, Universidad Central de Venezuela, Caracas, 1989; Judith Ewell, "Venezuela, 1930-c. 1990", en Bethell, Leslie (coord.), Historia de América Latina (Los países andinos desde 1930), Barcelona, Critica, 2002, Tomo16. 
Echeverría de México ${ }^{9}$, la experiencia chilena tuvo un significativo eco en la izquierda venezolana que manifestó masivamente su apoyo al gobierno de la UP, a través de marchas y declaraciones públicas. A su vez el ejemplo de esta última, potenció su organización y sus aspiraciones políticas de unidad de acción y adopción de una vía de intervención política pacífica e institucional.

En las semanas previas al golpe de Estado la prensa venezolana reseñó atentamente los avatares del gobierno de Salvador Allende: desde la intentona golpista del 29 de junio de 1973, pasando por la huelga de los dueños de camiones, hasta las propuestas de la oposición para salir de la crisis ${ }^{10}$. Durante todo el mes de septiembre los principales diarios de alcance nacional, El Nacional (de tendencia progresista) y El Universal (de tendencia conservadora), otorgaron amplios espacios en sus portadas y páginas interiores a la crisis chilena, al golpe de Estado y a los acontecimientos sucesivos. En el caso de El Nacional abordó los hechos de forma plural con notas destacadas sobre la posición de políticos de los distintos partidos venezolanos, ex presidentes de la República, dirigentes políticos destacados, el Vaticano, Moscú y Fidel Castro, entre otros. Es decir, el golpe de los militares chilenos no dejó indiferente a los principales agentes de poder y figuras políticas del ámbito nacional e internacional. Por su parte El Universal, relevó la posición del PDC chileno, partido análogo del Comité de Organización Política Electoral Independiente (COPEI) al que pertenecía el presidente Caldera, en diversos artículos que justificaban el cruento golpe de Estado con una clara intención de contrarrestar su impacto negativo a nivel nacional e internacional. Fue notable la campaña que realizó este periódico para demostrar que el golpe de Estado era la única opción posible para la democracia en Chile, apoyando tácitamente la actuación de la Junta Militar con la publicación de un extenso comunicado de la Embajada chilena los días 15 y 16 de septiembre, denostando al gobierno de la Unidad Popular (UP) y criminalizando a la izquierda chilena y latinoamericana en general y en particular a los colaboradores del presidente Allende. A continuación exhibimos fragmentos de algunos de los titulares, noticias y artículos de opinión que abundaron en las páginas de El Universal a lo largo del mes de septiembre de 1973:

EXTERIOR...La situación chilena. LOS EXCESOS DEL MARXISMO. Crearon el descontento militar. *Los jefes militares estaban constantemente en tensión.*La ola de atentados terroristas agravó el problema chileno.*'Patria y Libertad' nació el mismo día en que el dirigente Pablo Rodríguez fue vejado en un programa de TV.*La inflación era irresistible y el propio Allende denunció la gravedad del fenómeno" por Guillermo Ureta G. ${ }^{11}$.

Comunicado de la Embajada. JUNTA MILITAR DE CHILE EXPLICA LOS FUNDAMENTOS que motivaron su actuación.*El gobierno de Allende ha

\footnotetext{
${ }^{9}$ Fermandois, op.cit.

${ }^{10}$ El Nacional, Caracas, 4 de septiembre de 1973.

${ }^{11}$ El Universal, Caracas, 12 de septiembre de 1973, p.10.
} 
incurrido en grave ilegitimidad demostrada al quebrantar los derechos fundamentales de libertad de expresión, enseñanza, reunión, huelga, petición, propiedad y derecho, en general, a una digna y segura subsistencia, señala el documento...Caracas, 14 de septiembre de $1973^{12}$.

...Una fuente militar dijo a The Asocciated Press que había 'centenares de extranjeros detenidos, especialmente bolivianos, brasileños, uruguayos, cubanos y argentinos'. La Junta Militar afirmó que más de 10.000 extranjeros ingresaron al país bajo el gobierno de Allende para efectuar 'labores extremistas políticas'13.

...más de 13.000 extranjeros en situación irregular y en su gran mayoría extremistas, entre los cuales se indican las siguientes cifras: 4.178 bolivianos, 2.139 argentinos, 987 cubanos, 1.297 brasileños, 3.256 uruguayos, 580 colombianos, 148 mexicanos $^{14}$.

"El centro recuperó su animación. VOLVIÓ LA NORMALIDAD A SANTIAGO DE CHILE...”...Según documento encontrado en el Palacio presidencial, los izquierdistas tenían proyectado asesinar a varios jefes militares y a dirigentes de la oposición con motivo del desfile preparatorio de la Fiesta Nacional..." Primera Plana/portada del periódico ${ }^{15}$.

En lo que respecta al gobierno copeyano de Rafael Caldera, el Canciller Arístides Calvani se mostró templado y justificó su escaso pronunciamiento en relación al derrocamiento y muerte del presidente Allende, alegando "...somos celosos en respetar la autonomía e independencia de los demás pueblos...", pero era evidente que no se trataba de eso, sino del asalto al poder por medio de la violencia y de la remoción de un presidente electo bajo las normas de una democracia representativa, justamente el mismo régimen político que intentaba consolidarse en Venezuela desde 1958.

Por su parte, el día miércoles 12 de septiembre de 1973 el presidente Caldera decretó tres días de duelo nacional y declaró ante los periodistas:

...Manteniendo un precedente establecido en ocasiones similares de fallecimiento de jefes de Estado en el ejercicio del gobierno, dicté un Decreto de Duelo Oficial, y lo hice además, con la razón de querer hacer de esta manera público el sentimiento que el gobierno y el pueblo de Venezuela tienen, en este momento, por su trágica y lamentada desaparición...Es delicado, siempre, para un gobernante el emitir opiniones sobre los asuntos internos de otros países. Hemos sido y somos muy respetuosos del principio de no injerencia en asuntos ajenos. Ahora, el problema del reconocimiento, o sea de la continuación de relaciones, como se le llama ahora de una manera más precisa en los usos diplomáticos, es todavía prematuro emitir

\footnotetext{
${ }^{12}$ El Universal, Caracas, 15 y 16 de septiembre. Pp. 1-10

${ }^{13}$ El Universal, Caracas, 17 de septiembre de 1973, pp. 1-6

${ }^{14}$ El Universal, Caracas, 18 de septiembre de 1973, pp.1-10

${ }^{15}$ El Universal, Caracas, 18 de septiembre de 1973. Portada.
} 
cualquiera opinión o cualquiera información sobre el particular ${ }^{16}$.

Citamos aquí otros titulares ilustrativos de la posición asumida por la línea editorial de El Universal:

Dijo Caldera. YO LE OFRECÍ AL PRESIDENTE ALLENDE Mediar para que Dialogara con Algunos señalados dirigentes de Chile. *Profunda preocupación y angustia sienten los venezolanos ante la situación del hermano país. *Niega que el gobierno o COPEI hayan sabido del golpe. El viaje del ex ministro de Frei, Sergio Molina, no tuvo relación con los acontecimientos de Chile. ${ }^{*} \mathrm{La}$ situación surgida del golpe de Estado repercutirá negativamente dentro del enfoque general del continente. *Preocupante que comience a decirse ahora que la vía del cambio social sólo puede lograrse por la violencia ${ }^{17}$.

Y en el mismo sentido el dirigente copeyano y presidente de la Organización Demócrata Cristiana de América (ODCA) Luis Herrera Campins al ser interpelado por los sucesos de Chile afirmó que "consideraba la situación muy confusa y que en el curso del día de hoy podría emitir alguna declaración concreta" 18 .

A su vez, el partido Acción Democrática, el más importante del país, no tomó una postura oficial sobre el golpe en Chile, pero sus posiciones se expresaron a través de su presidente Gonzalo Barrios en estos términos:

...Examinamos la situación chilena. Siendo un gobierno legítimo y popular, el acontecimiento no puede verse con indiferencia, sino con reprobación, sin dejar de reconocer que las circunstancias económicas y sociales de Chile hacían prever estos sucesos, porque se hizo insostenible para amplios sectores de la clase media una adhesión al socialismo, mientras eran sometidos a pruebas de escasez y de privaciones. Dijo el doctor Barrios que $A D$ no asume ninguna moción oficial sobre el particular... ${ }^{19}$.

Una excepción a esta tendencia a no tomar posición fueron las declaraciones de Carlos Andrés Pérez, candidato adeco a las próximas elecciones presidenciales, quien repudio el golpe de Estado y realizó una defensa del sistema democrático, afirmando "sentirse conmovido por la angustia y la tragedia que vive el pueblo chileno" y señalando que:

La ola de gobiernos surgidos por métodos violentos sigue haciendo difícil y accidentado el trayecto hacia la superación de tantos males y

\footnotetext{
${ }^{16}$ El Universal, Caracas, 14 de septiembre de 1973, pp. 1-10 y El Nacional, Caracas, 14 de septiembre de 1973.

${ }^{17}$ El Universal, Caracas, 14 de septiembre de 1973, pp. 1-10 y El Nacional, Caracas, 14 de septiembre de 1973.

${ }^{18}$ El Nacional, Caracas, 12 de septiembre de 1973.

${ }^{19}$ El Nacional, Caracas, 12 de septiembre de 1973, portada. El resaltado es nuestro.
} 
vicios que padecen nuestros países...Como es bien sabido, yo no comparto las ideas que defendió el doctor Allende. Pero Allende llegó al poder por vía electoral y esto exigía respeto a su mandato... ${ }^{20}$.

Así, se observa que las posiciones de los partidos mayoritarios y del gobierno nacional rondaron entre la reprobación formal y moral del golpe de Estado y cierta justificación del mismo a causa de la ideología "marxista" o "la adhesión al socialismo" del gobierno constitucional y debido a la crisis económica, reforzada por la oposición y los Estados Unidos para desestabilizar la economía chilena. Este cuadro se completó con declaraciones del otro líder histórico de $\mathrm{AD}$, el ex presidente Rómulo Betancourt, quien en una desafortunada decisión envió un telegrama al general golpista Augusto Pinochet, reconociéndolo como presidente de facto, a través del cual le solicitaba entregar su pésame a la viuda e hijas de Salvador Allende "fallecido en trágicas circunstancias" 21 .

En contraste con las posiciones mayoritarias dentro de AD y COPEI, los partidos de la izquierda venezolana manifestaron en un acto público su condena del golpe militar y su homenaje a Salvador Allende y al pueblo de Chile, junto al recién depuesto embajador chileno en Venezuela, Luis Henríquez Acevedo. El acontecimiento fue reseñado en $E l$ Nacional de este modo:

Desde el doctor Luis Beltrán Pietro Figueroa [ex adeco y amigo de Allende durante 40 años], presidente del MEP [Movimiento Electoral del Pueblo], a Américo Martín del MIR [Movimiento de Izquierda Revolucionario]; desde Jesús Faría del PCV [Partido Comunista Venezolano], a Freddy Muñoz del MAS [Movimiento al Socialismo]; desde José Herrera Oropeza [secretario general de Nueva Fuerza] a Cruz Villegas [presidente de la Central Única de Trabajadores, CUT], destacaron que Salvador Allende, con su vida dedicada inquebrantablemente al socialismo, unió a la izquierda chilena que lo eligió Presidente de Chile, y ahora con su muerte, ayer, logró unir a los partidos venezolanos que no hacían actos juntos desde 1960...Jorge Rodríguez, del Frente Nacionalista Revolucionario, quien acaba de salir de la cárcel, dijo que lo que sucede en Chile es una advertencia para Venezuela y para América...22.

En aquel acto, Héctor Mujica, militante del PCV que había estado exiliado en Chile en los años cincuenta, también denunció que entre los detenidos en Chile se encontraban los estudiantes venezolanos Asdrúbal Grillet, Pablo Antillano, Horacio Mora y Frank Henríquez, y solicitó la intervención del gobierno para su auxilio inmediato. Asimismo, adhirieron al acto-homenaje prisioneros políticos de la izquierda recluidos en el cuartel militar de San Carlos ${ }^{23}$. Mientras que desde el mundo sindical, Cruz Villegas, presidente de

\footnotetext{
20 "Como demócrata repudio derrocamiento de Allende", El Universal, Caracas, 13 de septiembre de 1973, Exterior, pp. 1-6.

${ }^{21}$ El Nacional, Caracas, 13 de septiembre de 1973, portada.

${ }^{22}$ El Nacional, Caracas, 14 de septiembre de 1973.

${ }^{23}$ El Nacional, Caracas, 14 de septiembre de 1973.
} 
la pro-comunista CUT, en el mismo acto anunció que las centrales obreras convocarían a un paro nacional de solidaridad con Chile para el 18 de septiembre coincidiendo con el aniversario de la independencia de ese país. El 15 de septiembre El Nacional informó en una noticia destacada la convocatoria a un paro nacional de media hora de las centrales obreras de Venezuela en repudio del golpe de Estado y en apoyo de la clase obrera chilena $^{24}$. Paradojalmente la izquierda venezolana, fragmentada en variadas agrupaciones y partidos, se unía a instancia de la derrota de la izquierda chilena ${ }^{25}$.

En simultáneo, otros sectores de la sociedad civil venezolana, independientemente de los partidos políticos y del gobierno, manifestaron y expresaron de diversas formas su repudio frente a la ruptura del orden constitucional en Chile y los actos criminales que desde el inicio del golpe de Estado se desataron en contra de la población en general, como lo subrayaba esta crónica periodística:

...El embajador chileno recibió mensajes de solidaridad, pero se negó a comentar situación en su país, por carecer de información oficial...la representación diplomática fue visitada por estudiantes y personalidades de la vida nacional que quisieron manifestar su solidaridad con el presidente fallecido y su preocupación por los sucesos chilenos. Alrededor de las 10:30 de la mañana, estudiantes universitarios manifestaron frente a la Embajada chilena. Una representación de esos estudiantes hizo entrega al Embajador Henríquez Acevedo de un documento de solidaridad con Chile. A las cuatro de la tarde el Embajador Henríquez Acevedo recibió la visita de miembros del Consejo Universitario de la Universidad Central de Venezuela encabezados por el rector Rafael José Neri, quienes entregaron un mensaje de repudio al golpe de Estado y de solidaridad con el pueblo chileno... ${ }^{26}$.

Si bien la cuestión antiimperialista no estuvo ausente en la determinación de la solidaridad venezolana con la Unidad Popular $^{27}$ lo que pareció distinguir a Venezuela respecto de otros países del continente, fue que sus características políticas lo acercaban al clivaje político-ideológico chileno debido al perfil ideológico de los dos principales partidos: el Comité de Organización Política Electoral Independiente (COPEI), de tendencia democratacristiana y Acción Democrática (AD), socialdemócrata, vinculados con la Internacional Democratacristiana y la Internacional Socialista respectivamente. Por ende, en ese contexto político, lo que movilizó con gran fuerza la acción solidaria fue la recuperación de la democracia para Chile y la solidaridad con fuerzas políticas ideológicamente análogas como el Partido Demócrata Cristiano y el Partido Socialista de

\footnotetext{
${ }^{24}$ El Nacional, Caracas, 15 de septiembre de 1973.

${ }^{25}$ En aquellos años la izquierda venezolana estaba fragmentada en más de diez organizaciones nacionales, además de pequeños grupos locales y/o regionales. Véase: Elia Oliveros Espinoza, La lucha social y la lucha armada en Venezuela. 1958-1973, Caracas, Fundación Editorial El Perro y La Rana, 2012.

${ }^{26}$ El Universal, Caracas, 13 de septiembre de 1973, Exterior, pp. 1-6.

${ }^{27}$ Conversación con Sandra Palestro, hija del dirigente del Partido Socialista Mario Palestro, uno de los referentes del exilio chileno en Venezuela, Santiago de Chile, 12 de abril 2014.
} 
Chile, con los que se compartían articulaciones internacionales. Además, recordemos que fue también en Venezuela donde se constituyó en los años 1970-1973 una de las pocas coaliciones de izquierda de Latinoamérica influidas por la experiencia de la Unidad Popular chilena: la alianza del Frente Nacionalista Popular (FNP), integrada por el Movimiento Electoral del Pueblo-Partido Socialista de Venezuela (MEP), Unión Republicana Democrática (URD) y el Partido Comunista $(\mathrm{PCV})^{28}$.

Todos estos elementos contribuyeron a que la solidaridad política y sindical venezolana con las víctimas del golpe en Chile fuera destacada y receptiva por tratarse de una experiencia política vivida como cercana y reconocible políticamente. Esta interpretación y comprensión del proceso chileno contrastó con la recepción que tuvieron en Venezuela otros golpes de Estado seguidos de la instalación de Dictaduras de Seguridad Nacional, como veremos a continuación con el caso argentino. Esto es muy claro, por ejemplo, cuando se compara la recepción que tuvo el exilio chileno en Venezuela, en contraste con el recibimiento hecho al exilio argentino en el mismo país, donde influyeron factores como la recepción local de los procesos políticos que originaron los exilios, las relaciones a nivel de gobierno y fuerzas políticas y sociales y las características de cada comunidad exiliar. Por ejemplo, para los políticos y analistas venezolanos, las últimas décadas de la política argentina y el clivaje político de sus partidos e ideologías les resultaba confusa y de difícil interpretación, sobre todo, el peronismo, que albergaba en su interior la convivencia de sectores de ultraderecha y sectores de la guerrilla izquierdista ${ }^{29}$.

Así, a diferencia de casi todo el espectro político argentino de la época, cada fuerza política chilena que se exilió en países occidentales con regímenes de gobierno democráticos generalmente consiguió contar con la solidaridad de fuerzas de la misma matriz ideológica, con las que a menudo existían relaciones previas a 1973, y que no sólo se comprometieron en tareas de solidaridad y denuncia, sino que probablemente también influyeron en la orientación de los proyectos políticos de la oposición chilena en el exilio. Este fue otro elemento que asimiló el caso venezolano con los países de Europa, y la acogida que allí gozó la causa chilena ${ }^{30}$.

\section{La posición de Venezuela frente a los sucesos en la Argentina de 1976}

En el caso del golpe de Estado del 24 de marzo de 1976 en Argentina, en Venezuela el signo político del gobierno había cambiado y el presidente era el adeco Carlos Andrés Pérez (1974-1979). Sin embargo, éste continuó con la política contemporizadora con las dictaduras militares de la región que había iniciado Caldera con el régimen militar chileno

\footnotetext{
${ }^{28}$ Véase al respecto Jorge Gaspar, “Conversación sobre la Nueva Fuerza y su programa”, Nueva Sociedad, julio-agosto $1972, \mathrm{~N}^{\circ} 1$, pp. 25-27.

${ }^{29}$ Como recordaba Nicolás Casullo un exiliado de la izquierda peronista que llegó a Caracas en 1975 huyendo de las amenazas de la organización parapolicial ultraderechista y peronista Triple A: "a los venezolanos el país les parecía lejano, de desarrollo medio y europeizado". Testimonio de Nicolás Casullo en Eduardo Anguita y Martín Caparros, La Voluntad. Una historia de la militancia revolucionaria en la Argentina (Tomo 4), Buenos Aires, Booket, tercera edición, 2009 [1998]. p. 304.

${ }^{30}$ Rojas Mira, Claudia y Santoni, Alessandro, "Geografía política del exilio chileno: Los diferentes rostros de la solidaridad”, Perfiles Latinoamericanos, № 41, enero-junio 2013, FLACSO, México.
} 
y decidió reconocer al gobierno militar producto del golpe y mantener las relaciones diplomáticas y consulares, guardando silencio sobre la interrupción del gobierno constitucional.

En contraste con el caso de Chile, el golpe de Estado en Argentina fue recibido por la prensa y las fuerzas políticas y sindicales venezolanas con cierta sensación de inevitabilidad. Fue tratado casi como un golpe anunciado e interpretado dentro de la tradición de golpes militares que vivía la Argentina desde 1930 y como resultado de la coyuntura de crisis económica y política de los últimos años, en los cuales la conflictividad obrera y la violencia política guerrillera fueron enfrentadas con brutales mecanismos de represión estatal y paraestatal por un gobierno peronista deslegitimado, cuyas repercusiones en Venezuela se tradujeron en un incremento de los flujos de migrantes económicos y desterrados políticos de origen argentino.

Desde diciembre de 1975 los rumores de golpe de Estado y el ultimátum de los jefes militares al gobierno de Isabel Martínez de Perón (1974-1976) eran internacionalmente conocidos. Por ejemplo, el día previo al golpe de Estado, el martes 23 de marzo de 1976, El Universal rotulaba en su portada "Se acentúan los rumores de Golpe en Argentina"; y publicaba un artículo titulado "Y siguen los atentados: 1.360 muertos desde 1973 por la violencia en Argentina"31. Mientras que El Nacional del mismo día anunciaba en su tapa "Movimientos de tropas en Argentina" y describía el ambiente como cruzado por "versiones golpistas sin precedentes", un "tiroteo generalizado entre guerrilleros y fuerzas de seguridad en La Plata" y el "vencimiento del plazo de tres meses" para resolver la crisis institucional dado por los militares al gobierno de Martínez de Perón. Y completaba el cuadro de situación informando sobre la movilización de tropas y la ocupación de edificios públicos y lugares estratégicos, con silencio de la cúpula militar y de "un gobierno legal desorientado",32.

El 24 de marzo, día del golpe, la portada de El Universal tituló "Inminente golpe militar- Acuartelado el ejército argentino" y destacaba lo complejo del escenario argentino al señalar la campaña pro golpe de Estado de los principales medios de comunicación y su extraña competencia para pronosticar de forma acrítica el día preciso de la ruptura del orden constitucional y los planes de los militares ${ }^{33}$. El Nacional de ese día compartía la misma percepción de inevitabilidad e incomprensión por el desarrollo de los sucesos, interpretándolos como parte de la dinámica política argentina de intervenciones militares frecuentes. Pero en cambio brindó una cobertura extensa y detallada. Por ejemplo destacó que las posiciones de la Unión Cívica Radical (UCR) -partido de tendencia liberal conservadora, el más importante después del peronista- no condenó los rumores de golpe y en cambio aprovechó la ocasión para convocar a la formación de una "Asamblea Multipartidaria" en torno de Ricardo Balbín, su presidente, la cual propondría gobernar el país a través de "la formación de una comisión bicameral que se encargará de ejecutar, a nivel parlamentario, las decisiones que puedan surgir de la Asamblea Mulpartidaria". A su vez, también informó que la noche del 23 de marzo la presidenta Martínez de Perón y su

${ }^{31}$ El Universal, Caracas, 23 de marzo de 1976.

${ }^{32}$ El Nacional, Caracas, 23 de marzo de 1976.

${ }^{33}$ El Universal, Caracas, 24 de marzo de 1976. 
gabinete evaluaban convocar a elecciones generales anticipadas para el 12 de diciembre ${ }^{34}$.

El jueves 25 de marzo El Nacional continuó con su cobertura del golpe militar argentino. La portada fue "La Junta militar disolvió el Parlamento Argentino", y agregaba que había instaurado la pena de muerte, la censura de los medios de comunicación, encarcelamientos y redadas masivas, y la "suspensión" de la actividad de todos los partidos políticos y de organizaciones empresariales, sindicales y profesionales. La nota de su corresponsal enviado a Buenos Aires para cubrir los confusos hechos resumía una sensación extendida en vastos sectores venezolanos: "Completado el cerrojo militar en el Cono Sur. Queda la sensación de sentirnos cada vez más aislados en nuestra excepcional democracia venezolana" 35 . En las semanas siguientes el diario dedicó varios artículos de diversas opiniones acerca de las razones del golpe, cronologías del gobierno peronista, el perfil y proyecto de la junta militar, la situación represiva masiva y las implicancias del golpe de Estado para la región.

La posición de la dictadura militar se hizo pública a través de El Nacional en un comunicado titulado "Justificación del derrocamiento y lineamientos generales del nuevo gobierno argentino", que fue entregado al diario por un desvelado funcionario de la Embajada argentina a última hora del 24 de marzo, y que afirmaba lo siguiente:

Frente al caos institucional, social y administrativo que vivía la república, la junta militar, integrada por los comandantes generales de las tres Fuerzas Armadas, ha decidido asumir el gobierno de la nación Argentina.

La acción del gobierno estará caracterizada por la vigencia plena de la ley, en un marco de orden y respeto de la dignidad humana. Su objetivo fundamental será restituir los valores esenciales que hacen a los fundamentos de la conducción del Estado, asegurando el desarrollo pleno de las potencialidades naturales y humanas que conforman el país.

La Junta militar, en ejercicio del gobierno, respetará plenamente y en todo su alcance, los compromisos internacionales contraídos por la República Argentina, asegurando la vida, los bienes y los intereses de los extranjeros radicados en el país, en estricto cumplimiento de la normas vigentes en el Derecho Internacional ${ }^{36}$.

Como queda en evidencia, los militares golpistas se presentaban de forma moderada y justificaban la destitución del gobierno legal por las crisis políticas y el "caos" y prometían que su gobierno se caracterizaría por "la vigencia de las leyes", mientras en secreto iniciaba una feroz represión clandestina y masiva con el objetivo de asesinar opositores que dejó un saldo de decenas de miles de desaparecidos, presos políticos y exiliados ${ }^{37}$.

\footnotetext{
${ }^{34}$ El Nacional, Caracas, 24 de marzo de 1976.

${ }^{35}$ El Nacional, Caracas, 25 de marzo de 1976.

36 "Justificación del derrocamiento y lineamientos generales del nuevo gobierno argentino", El Nacional, Caracas, 25 de marzo de 1976.

${ }^{37}$ Para un análisis de la metodología represiva de la última dictadura argentina véase: Pilar Calveiro, Poder y
} 
Las posiciones de los partidos políticos venezolanos frente al golpe argentino fueron de preocupación por sus efectos regionales -sólo en Venezuela, Costa Rica y Colombia sobrevivían gobiernos democráticos- y señalaron la responsabilidad del gobierno peronista y de las guerrillas en la situación que llevó a la intervención militar. Así, Oswaldo Álvarez Paz, diputado nacional y dirigente nacional de COPEI, afirmaba que "Para Venezuela es preocupante el naufragio de una experiencia en Sudamérica"; y David Morales Bello, de $\mathrm{AD}$, "la caída de la señora Perón advierte a quienes muchas veces acosan la democracia perdiendo la perspectiva"; mientras que Luis Beltrán Prieto Figueroa, del MEP, expresó: "Si los militares fueran razonables llamarían al pueblo a elecciones". Por otro lado, Germán Lairet, del MAS, opinó "La derecha peronista facilitó el camino"; y por otro lado Rondón Lovera recalcaba: "La ultraizquierda contribuyó con sus acciones anárquicas a desestabilizar el régimen”. Gonzalo Barrios, jefe de AD, también expresó su lamento por la ruptura constitucional, calificando al golpe de inevitable y responsabilizando al gobierno de Martínez de Perón, para finalizar afirmando que esperaba que los militares dejaran pronto el poder y regresara la democracia ${ }^{38}$. A su vez días más tarde Luis Herrera Campins, jefe de la bancada parlamentaria de COPEI y dirigente de la red de partidos socialcristianos de América Latina, declaró que "Gobierno y oposición tenemos que meditar sobre las consecuencias de lo que está pasando en América Latina"39.

Nuestro relevamiento de la prensa venezolana en relación al tema también dejó en claro el silencio de otros actores importantes como el PCV y el mismo gobierno de Carlos Andrés Pérez. Esta vez los partidos de la izquierda venezolana no se unieron para condenar el golpe y expresar su solidaridad con el gobierno derrocado, cuyos funcionarios eran mayormente políticos y sindicalistas derechistas corruptos que permanecieron en el país después del golpe. Tampoco expresaron apoyo a ninguno de los partidos de la izquierda parlamentaria argentina -el Partido Comunista Argentino declaró su apoyo al régimen militar en los días posteriores el golpe- o a las diezmadas organizaciones guerrilleras que llamaron a la resistencia armada contra la dictadura.

Como expresábamos más arriba, la situación política argentina se mostraba confusa y compleja para la mayoría de los políticos y analistas venezolanos. Pocos de ellos conocían y se interesaron por la realidad política argentina donde no tenían referentes y relaciones, a diferencia de lo que sucedió con la UP chilena. Pero hubo algunas excepciones. Una de ellas fue el MEP, cuyos dirigentes tenían un amplio conocimiento de la historia y la política argentina. Precisamente el día posterior al reconocimiento de la dictadura militar por el gobierno venezolano, Jesús Paz Galarraga expuso su posición en un artículo en El Universal, en el cual no dudó en caracterizar que "en el orden latinoamericano la Junta Militar argentina completa el cuadro fascistoide del cono sur del continente" y de señalar que el golpe se realizó "con la bendición del Departamento de Estado, todo lo cual es preocupante para el futuro de Venezuela"; y concluyó:"Vendrá la

desaparición: los campos de concentración en Argentina, Buenos Aires, Colihue, 1a ed. 2a reimp, 2004[1995].

38 Alfredo Peña "Líderes políticos condenan el golpe militar en Argentina”, El Nacional, Caracas, 25 de marzo de 1976.

${ }^{39}$ El Nacional, Caracas, 28 de marzo de 1976. 
resistencia organizada, la cual necesitará de un largo tiempo para triunfar en virtud de las profundas divisiones surgidas en los sectores progresistas y revolucionarios" 40 .

Otra excepción en el campo de la izquierda fueron las intervenciones de José Herrera Oropeza abogado, periodista, político de izquierda y defensor de los derechos humanos que formaba parte del Tribunal Russell II, ${ }^{41}$ quien tomando el ejemplo de la posición del gobierno venezolano ante el golpe en Argentina criticó la política exterior de Pérez en relación al Tercer Mundo y América Latina, definiéndola como contradictoria e incoherente. Según Herrera Oropeza el lineamiento de la integración económica, por ejemplo, era contradictorio con "la lógica interna del capitalismo rentístico controlado por las transnacionales, el endeudamiento externo y el derroche burocrático que indicaban una profundización de la dependencia"42. Y a su vez -continuaba- la cuestión de la pluralidad ideológica llevaba a reconocer a gobiernos dictatoriales que impugnaban el régimen de gobierno venezolano, mientras que en el ámbito interno el mismo gobierno no respetaba la seguridad de las víctimas de las dictaduras asiladas en el territorio nacional y ponía como ejemplo el caso de los exiliados chilenos, afirmando:

Tampoco armoniza con el hostigamiento a exiliados chilenos en Venezuela según lo han denunciado numerosos parlamentarios de oposición, militantes de distintas tendencias. Y una política así, dual, sin uniformidad, ni coherencia, no conviene a nadie. [...] Algunos analistas muestran la grave inquietud que ha generado el reciente golpe militar en Argentina, pues este se traduce en una nueva victoria de la acción envolvente brasileña sobre América Latina respaldada por el secretario de Estado norteamericano. [...Finalizando:] Quizás sea una necedad decir una vez más que AD como partido mayoritario en el gobierno le quedan dos caminos: o se deja arrollar definitivamente por los factores de poder internacional o sigue la vía de la independencia integral. El primero es aislacionista. El segundo integracionista. Pero no habrá otro y menos se podrá continuar nadando entre dos aguas ${ }^{43}$.

El mundo sindical venezolano tuvo reacciones diversas ante el golpe militar argentino. Ni la Confederación de Trabajadores de Venezuela (CTV), controlada por AD y COPEI, ni la CUT, dominada por el PCV, realizaron declaraciones oficiales sobre el golpe de Estado. Sin embargo, el golpe y la dictadura argentina tuvieron un tenaz y sistemático opositor en la Central Latinoamericana de los Trabajadores (CLAT), sede regional de la Confederación Mundial del Trabajo (CMT), cuyas organizaciones afiliadas a nivel local formaban una corriente importante dentro de la CTV bajo la denominación de Confederación de Sindicatos Autónomos de Venezuela (CODESA), formando parte de sus órganos

\footnotetext{
${ }^{40} J e s u ́ s$ Paz Galarraga, "La experiencia argentina”, El Universal, Caracas, 1 de abril de 1976.

${ }^{41}$ Alberto Garrido (Comp.), Exilio, nostalgia y creación, Mérida, Dirección de Cultura de la Universidad de los Andes, 1987, pp. 7-8.

${ }^{42}$ José Herrera Oropeza, "La política exterior", El Nacional, Caracas, 9 de abril de 1976.

${ }^{43}$ Idem.
} 
ejecutivos $^{44}$. La CLAT-CMT reclamó desde el inicio de la última dictadura militar argentina por los derechos de los trabajadores, denunció la intervención de los sindicatos y la política represiva de asesinatos, desapariciones y encarcelamientos de obreros y sindicalistas ante organismos internacionales, gobiernos extranjeros y la opinión pública internacional $^{45}$. En paralelo brindó contactos, relaciones y recursos para apoyar la salida y sostenimiento en el exterior de militantes sindicales, y envió a la Argentina varias misiones de observación y solidaridad entre 1976 y $1983^{46}$. También condenaron y denunciaron la complicidad de la URSS, la CPUSTAL y el Partido Comunista Argentino (PCA) ${ }^{47}$ y de los Estados Unidos y la ORIT, con la política laboral y represiva de la dictadura argentina ${ }^{48}$.

Por su parte el gobierno de Carlos Andrés Pérez no hizo pública ninguna declaración oficial ante el golpe de Estado y la interrupción del gobierno constitucional de uno de los principales países de la región. El mismo 25 de marzo, el Canciller venezolano Ramón Escovar Salom anunció a los medios de comunicación locales que el gobierno reconocería próximamente a la Junta Militar argentina. Finalmente, el 31 de marzo, un día después de la asunción de Jorge R. Videla como "presidente" nombrado por la Junta Militar, Venezuela reconoció a la dictadura militar en un comunicado escueto en el cual explicaba: "se ha comisionado al embajador de Venezuela en Argentina, Ernesto Santander, para que informe al nuevo gobierno la decisión. El reconocimiento implica la continuación de las relaciones diplomáticas y consulares entre ambas naciones"49. La declaración se hacía luego de que Estados Unidos, España y Brasil habían reconocido "automáticamente" a la Junta Militar.

\footnotetext{
${ }^{44}$ La CLAT-CMT tenía una orientación socialcristiana e inspirada en la doctrina del humanismo integral, no alineada, tercermundista, políticamente partidaria de una democracia integral y de un modelo socioeconómico autogestionario con participación de los trabajadores. Véase: Gabriela Scodeller, "La CLASC/CLAT", en Revista Europea de Estudios Latinoamericanos y del Caribe, No. 98, Abril 2015; Mario Ayala, "La solidaridad sindical venezolana con Argentina durante la última dictadura cívico-militar. El caso de la Central Latinoamericana de Trabajadores (CLAT)", ponencia en: IX Seminario Internacional Políticas de la Memoria, Buenos Aires, Centro Cultural de la Memoria Haroldo Conti , noviembre de 2016.

${ }^{45}$ Ante el golpe militar de marzo de 1976 la central se declaró en estado de alerta permanente para acciones de solidaridad concretas con el movimiento obrero argentino "a fin de expresar en acciones concretas la solidaridad con el pueblo y los trabajadores de Argentina, según lo vaya indicando el curso de los acontecimientos en ese país". CLAT, "La CLAT solidaria con el pueblo y los trabajadores argentinos", Informativo CLAT. Vocero del movimiento de los trabajadores comprometidos con la liberación de los pueblos de América Latina, Año 1, N¹, abril, 1976, p. 1. En: Instituto Internacional de Historia Social (IISH) de Ámsterdam, Holanda. Agradecemos a la Gabriela Scodeller (Universidad de Buenos Aires-CONICET) y a Matías Oberlin por habernos facilitado la documentación de la CLAT que permitió reconstruir este proceso.

${ }^{46}$ Ayala, op. cit.

${ }^{47}$ Aunque no es el tema central de este apartado la prensa de la CLAT muestra también la existencia de una sostenida denuncia de las políticas de las centrales sindicales internacionales CIOLS-ORIT y FSMCPUSTAL en relación a las dictaduras y gobiernos autoritarios, junto con la política regional de EEUU y la URSS, que en Argentina era defendida por el PCA y su particular lectura de la dictadura. De modo que al mismo tiempo que denunció a la dictadura, también los hizo con sus aliados internos e internacionales: la URSS y el PCA y los Estados Unidos y la ORIT. Véase: CLAT: 1978. "Ocultan las violaciones de Derechos Humanos en Argentina", Informativo CLAT. Vocero del movimiento de los trabajadores comprometidos con la liberación de los pueblos de América Latina, Año 3, N²2, Marzo, p. 18.

48 Ayala, op. cit.

49 "Venezuela reconoció al gobierno argentino", El Universal, del $1^{\circ}$ de abril de 1976.
} 
Luego del golpe de Estado de marzo de 1976 y la instauración de una dictadura, la posición del gobierno venezolano fue de búsqueda del mantenimiento de las relaciones diplomáticas regulares y de una relación bilateral de reconocimiento, acercamiento y no confrontación. Los altos funcionarios y embajadores venezolanos del periodo 1974-1979 desvincularon primero al gobierno peronista y después a la Junta Militar de las persecuciones, asesinatos y desapariciones, atribuyendo su responsabilidad a sectores ultraderechistas de las fuerzas armadas y de seguridad que escapaban al control del gobierno $^{50}$ y reprodujeron la justificación de la dictadura según la cual la represión y el Estado de excepción eran una respuesta a la amenaza subversiva que estaba siendo derrotada y huía al exterior. Una de las consecuencias de esta caracterización de la situación argentina fue una aplicación restrictiva del asilo diplomático y territorial para los perseguidos y presos políticos del régimen militar ${ }^{51}$. Posteriormente estas relaciones bilaterales fueron reforzadas por la decisión del gobierno de Pérez de continuar con los lineamientos de política internacional de su antecesor y se expresaron en una serie de iniciativas que buscaban incrementar los intercambios comerciales y tecnológicos y llegaron a su pico más alto con la invitación oficial a Videla para que visitara Venezuela en mayo de $1977^{52}$.

\section{Conclusiones}

Este artículo abordó la recepción que tuvieron los golpes de Estado ocurridos en Chile (1973) y la Argentina (1976) en Venezuela, a nivel de los principales diarios de tirada nacional, de las fuerzas políticas, sindicales y de los gobiernos.

En el caso del golpe en Chile, un hecho político de amplia repercusión mundial, las líneas editoriales de los diarios El Nacional y El Universal fueron desde el rechazo al golpe, la búsqueda de explicaciones hasta su justificación, dependiendo de los alineamientos políticos de cada uno de ellos y de cuán cercanos estaban al gobierno socialcristiano de Rafael Caldera, que mantuvo posiciones cercanas a las del ala derecha de la DC chilena que apoyó el golpe militar. La postura de los partidos mayoritarios (COPEI y AD) y del gobierno nacional (COPEI) rondó entre la reprobación formal y moral del golpe de Estado chileno y cierta justificación del mismo a causa de la ideología "marxista" o "la adhesión al socialismo" del gobierno constitucional y debido a la crisis económica. Mientras que los partidos y sindicatos de izquierda repudiaron el golpe chileno de forma unitaria y

\footnotetext{
${ }^{50}$ La dictadura mantuvo cierta legitimidad interna, entre otras cosas por la censura y la desinformación. A lo que se sumó la estrategia de represión clandestina y la negación de la responsabilidad gubernamental. Entre los embajadores del periodo también predominaba la percepción de la existencia de sectores moderados, duros y ultra duros entre los militares, considerando a Videla como un moderado al que indirectamente convenía sostener frente a opciones más autoritarias y duras respecto a las libertades, la represión y la apertura democrática.

${ }^{51}$ Mario Ayala, "Pedidos de asilo, refugio y visas en la embajada de Venezuela en la Argentina (1974-1983", ponencia en II Jornadas de Trabajo sobre Exilios Políticos del Cono Sur en el siglo XX. Agendas, problemas y perspectivas conceptuales, Montevideo, Facultad de Humanidades y Ciencias de la Educación, Universidad de la República, 5, 6 y 7 de noviembre de 2014.

52 Idem.
} 
declararon su solidaridad con el gobierno derrocado y los partidos integrantes de la coalición de la Unidad Popular. Así, en sintonía con la movilización de la opinión pública mundial frente el golpe en Chile, la esfera pública venezolana fue sensible a los sucesos, porque el golpe chileno fue entendido como una grave ruptura institucional de un país percibido con una sólida tradición democrática y de un proceso de vía pacífica y democrática al socialismo, por tanto la solidaridad fue transversal. Y como resultado, todos estos elementos contribuyeron a que buena parte de los partidos políticos y sindicatos se solidarizaran con el gobierno derrocado y sus fuerzas políticas, por tratarse de una experiencia política vivida como cercana y reconocible políticamente. Esta interpretación y comprensión del proceso chileno contrastó con la recepción que tuvieron en Venezuela otros golpes de Estado seguidos de instalación de Dictaduras de Seguridad Nacional, como con el caso argentino.

En cuanto al golpe de Estado en la Argentina, se observaron importantes contrastes con respecto a la recepción del golpe chileno. En primer término, la prensa nacional y prácticamente todo el espectro de partidos políticos venezolanos interpretó el acontecimiento como un casi inevitable desenlace ante la crisis económica y política, el caos y la represión y la violencia estatal desatadas por el gobierno peronista con la justificación de combatir las actividades de los grupos guerrilleros. Además, a diferencia de Chile que era considerado una de las democracias más estables de América Latina, el golpe militar en Argentina fue enmarcado como parte de una tradición local de intervenciones militares en los gobiernos argentinos desde 1930. A lo que sumaba que la junta militar argentina a diferencia de la chilena, no dio un golpe cruento con actos de represión pública y asesinato y exilio del gobierno derrocado, sino que contó con el apoyo de una parte importante de los partidos políticos parlamentarios (desde la Unión Cívica Radical hasta el Partido Comunista) y realizó una represión clandestina negando su autoría, lo cual hizo más confusa la lectura de los acontecimientos y los posicionamientos, más allá de los deseos de una pronta recuperación de la democracia. En tercer lugar se observó que la mayoría de los actores analizados aceptaron el discurso justificatorio del golpe dado por la dictadura militar, a la que no responsabilizaron directamente por los secuestros, asesinatos y detenciones secretos que se masificaron después del golpe y continuaron en los siguientes años. Con esa lógica el golpe argentino fue entendido como una continuidad y fundamentado en crisis previas. Por tanto, la solidaridad fue escasa y puntual.

La recepción de los golpes de Estado, por parte de los gobiernos venezolanos de Rafael Caldera y Carlos Andrés Pérez, tuvo sus especificidades dependiendo de si se trató del golpe de Estado chileno o del argentino y de cada uno de los respectivos presidentes venezolanos. No obstante frente a ambas coyunturas, prevalecieron actitudes ambiguas, cautelosas y discretas en cuanto al rechazo de la violencia desatada y también actitudes que contemplaron razones políticas de Estado, en tanto Venezuela se preciaba de ser un país democrático que no podía aparecer ante la mirada del mundo aceptando la barbarie de los militares chilenos y argentinos. Desde su redemocratización en 1958 los gobiernos de Venezuela proyectaban internacionalmente la imagen de país democrático y abierto que respetaba los derechos humanos y el pluralismo ideológico. Sin embargo, el análisis de la 
posición venezolana ante los golpes de Estado en el Cono Sur de América Latina pone al descubierto las contradicciones de la política exterior e interior que generó el tema y es evidente que los golpes militares de Chile y Argentina no recibieron una condena enérgica de parte de los gobiernos venezolanos de Rafael Caldera-COPEI y Carlos Andrés PérezAD.

Finalmente hemos querido aportar con este texto, al debate latinoamericano sobre nuestra historia reciente comparando la posturas de actores estatales y no estatales de Venezuela hacia dos países del Cono Sur, con el fin de facilitar una mayor comprensión de fenómenos y procesos históricos de la región. Este ejercicio intelectual ha permitido conocer la recepción de los golpes de Estado en la sociedad venezolana, facilitando la comprensión de diversas cuestiones. La primera de ellas, relacionada con las percepciones locales diferenciadas respecto de cada comunidad nacional, que condicionaron desde el apoyo gubernamental, hasta la solidaridad política y sindical con fuerzas políticas y sociales en el interior y exterior de cada país. Una segunda, es que nos ayuda a entender otras consecuencias que tuvieron la caída de los gobiernos democráticos del Cono Sur en Venezuela, tales como las presiones por asilos y los flujos de exiliados y migrantes que comenzaron a buscar ingresar en el país después de cada Golpe de Estado. El artículo permite observar cómo fue el impacto de los golpes chileno y argentino en las esferas públicas y políticas locales de países de la región y observar los imaginarios y representaciones sociales venezolanos en relación a cada uno de los países del Cono Sur y las alianzas o solidaridades internacionales de los gobiernos, partidos y sindicatos locales. Igualmente, nuestra reflexión frente a los sucesos de los años setenta analizados, ha permitido considerar que la recepción que tuvieron tales golpes de Estado por parte del gobierno venezolano, sentó las bases para que no se rompieran relaciones diplomáticas con la junta militar chilena y la argentina.

\section{Bibliografía}

Aguirre, Arturo; Sánchez Cuervo, Antolín y Roniger, Luis, Tres estudios sobre el exilio: condición humana, experiencia histórica y significación política, Madrid-México, EDAF-BUAP, 2014.

Anguita, Eduardo; Caparros, Martín, La Voluntad. Una historia de la militancia revolucionaria en la Argentina (Tomo 4), Buenos Aires, Booket, tercera edición, 2009 [1998].

Ayala, Mario, "Pedidos de asilo, refugio y visas en la embajada de Venezuela en la Argentina (1974-1983)", ponencia en II Jornadas de Trabajo sobre Exilios Políticos del Cono Sur en el siglo XX. Agendas, problemas y perspectivas conceptuales, Montevideo, Facultad de Humanidades y Ciencias de la Educación, Universidad de la República, 5, 6 y 7 de noviembre de 2014.

Ayala, Mario, "La solidaridad sindical venezolana con Argentina durante la última dictadura cívicomilitar. El caso de la Central Latinoamericana de Trabajadores (CLAT)", ponencia en: IX Seminario Internacional Políticas de la Memoria, Buenos Aires, Centro Cultural de la Memoria Haroldo Conti, noviembre de 2016. 
Ayala, Mario; Rojas Mira, Claudia, “...o el asilo contra la opresión...: El asilo político de chilenos y argentinos en las embajadas venezolanas de los años setenta", ponencia presentada en: III Jornadas de Trabajo sobre Exilios Políticos del Cono Sur en el siglo XX. Agendas, problemas y perspectivas conceptuales, Santiago de Chile, Museo de la Memoria y los Derechos Humanos, 9, 10 y 11 de noviembre de 2016.

Calveiro, Pilar, Poder y desaparición: los campos de concentración en Argentina, Buenos Aires, Colihue, 1a ed. 2a reimp., 2004[1995].

Ewell, Judith, "Venezuela, 1930-1990", en Bethell, Leslie (coord.), Historia de América Latina (Los países andinos desde 1930), Barcelona, Critica, 2002, Tomo16.

Fermandois, Joaquín, Chile y el mundo 1970-1973. La política exterior del gobierno de la Unidad Popular y el sistema internacional. Santiago, Universidad Católica de Chile, 1985.

Gamus, Raquel, "El contenido de la política exterior de Carlos Andrés Pérez (1974-1979)", Anuario del instituto de Estudios Hispanoamericanos, Ediciones de la Facultad de Humanidades y Educación, Universidad Central de Venezuela, Caracas, 1989.

Garrido, Alberto (Comp.), Exilio, nostalgia y creación, Mérida, Dirección de Cultura de la Universidad de los Andes, 1987.

Gaspar, Jorge, "Conversación sobre la Nueva Fuerza y su programa”, Nueva Sociedad, julio-agosto 1972, $\mathrm{N}^{\circ} 1$, pp. 25-27.

Harmer, Tanya, Allende's Chile and the inter-American cold war. North Carolina, The University of North Carolina Press, 2011.

Lastra, María Soledad, Los retornos del exilio en Argentina y Uruguay. Una historia comparada de las políticas y tensiones en la recepción y asistencia en las pos dictaduras (1983-1989), Tesis para optar por el grado de Doctora en Historia, La Plata, Argentina, Universidad Nacional de La Plata, 2014.

Maier, Charles S., "La historia comparada", en Studia Historica-Historia Contemporánea, Vol. XXI (1992-93) pp. 11-32.

Mc Sherry, Patrice J., "La maquinaria de muerte: la Operación Cóndor", Taller (Segunda Época). Revista de Sociedad, Cultura y Política en América Latina, Vol. 1, Nº1 (octubre), 2012, pp. 33-45.

Nocera, Raffaele, "11 de septiembre de 1973: incomprensiones y ambigüedades entre la DC chilena y la italiana", en Izquierdas, No 24, 2015, p. 5.

Oliveros Espinoza, Elia, La lucha social y la lucha armada en Venezuela. 1958-1973, Caracas, Fundación Editorial El Perro y La Rana, 2012.

Pilar Calveiro, Poder y desaparición: los campos de concentración en Argentina, Buenos Aires, Colihue, 1a ed. 2a reimp, 2004[1995]. 
Mario Ayala - Claudia Rojas: La recepción de los golpes de Estado de Chile y Argentina en Venezuela: prensa, actores políticos y gobiernos (1973/1976), Izquierdas, 33, mayo 2017, pp. 1-20

Rojas Mira, Claudia y Santoni, Alessandro, "Geografía política del exilio chileno: Los diferentes rostros de la solidaridad", Perfiles Latinoamericanos, № 41, enero-junio 2013, FLACSO, México.

Scodeller, Gabriela, "La CLASC/CLAT", en Revista Europea de Estudios Latinoamericanos y del Caribe, No. 98, Abril 2015.

Slatman, Melisa, "Terrorismo de Estado y exilio: hipótesis exploratorias para una comparación entre los casos chileno y argentino", Ponencia presentada en Jornadas de trabajo sobre Exilios Políticos del Cono Sur en el siglo XX. Agendas, problemas y perspectivas conceptuales, Facultad de Humanidades y Ciencias de la Educación de la Universidad Nacional de La Plata, 26, 27 y 28 de septiembre de 2012 .

Spenser, Daniela (ed.), Espejos de la Guerra fría, México, América Central y el Caribe, México, CIESAS, 2004.

Westad, Odd Arne, The Global Cold War. Third World Interventions and the Making of our Times, Cambridge, Cambridge University Press, 2007.

Diarios y revistas citadas

El Nacional, Caracas, Venezuela, 1973/1976.

El Universal, Caracas, Venezuela, 1973/1976.

Informativo CLAT. Vocero del movimiento de los trabajadores comprometidos con la liberación de los pueblos de América Latina, Caracas, Venezuela, 1976.

Nueva Sociedad, Caracas, Venezuela, 1972. 